\title{
International Institute of Welding
}

\section{CHAIRMEN'S REPORTS}

\section{COMMISSION XIV-Welding instruction}

Lausanne Assembly (Switzerland) : 13-19 July 1970

Chairman : Prof. R. B. McCauley (United States)

\section{Introduction}

The annual meetings of Commission XIV were held on the occasion of the Annual Assembly of the International Institute of Welding in Lausanne from 16 to 19 July 1970 . They were attended by 43 delegates, experts, observers and temporary experts from 20 different countries. Two countries tied for top honours in representation, namely Germany and the United Kingdom with four each. Four countries had three members each in attendance.

An important contribution to the success of the Lausanne meeting was the intermediate meeting of the Commission held in Paris on 14 and 15 January, 1970. This coordination meeting clearly defined the scope of the Lausanne agenda and clarified the Commission's time table. The Commission is grateful to the Governing Council for its permission to revise its annual programme and to specialise on a particular theme at each Assembly. The theme of the Lausanne meeting was "Training, classification and qualification of welding operators". The Working Group on Welder Classification and Qualification was cited for its important contribution to consolidating opinion within the Commission.

\section{Training, Classification and Qualification of Welding Operators}

The above title was the main theme of the Commission meetings held in Lausanne. Four documents on the training of welding operators were discussed :

XIV-279-69 "English translation of German Standard DIN 8560 (Aug. 1968) "Examination of welders for welding steel"

XIV-287-70 "Welding operator courses in the United States"

XIV-290-70 "Training of welding operators. The industrial module training system in the United Kingdom" by L. M. Gourd (United Kingdom)

XIV-292-70 "L'enseignement professional industrial en soudure et techniques connexes en Espagne, Professional training in welding and allied processes in Spanish industry".

These documents dealt with training schemes in Germany, Spain, United Kingdom and United States. Comments from participants enabled comparisons to be drawn with the various training programmes in member countries. While agreeing that initial training gave a good idea of a trainee's capabilities, the Commission felt that it was not sufficient to determine the level of skill as an operator. It was therefore essential to plan a progressive programme which would incorporate 
supervised industrial experience as well as further training. The extent and nature of tests to be given at the end of an initial training period varied from country to country. One common denominator was the length of the training period and the type of test. Course programmes were more efficient when directed towards specific needs.

Delegates felt that the Commission should attempt to formulate some basic training principles; on this subject it was considered that agreement could be reached on the basis of minimum requirements for the training of operators. It was felt that the age of the trainee and the type of welding done by him were important factors which would lead to a sub-division of training programme. The basic stages agreed upon were (1) initial training, (2) supervised experience, (3) further training, (4) qualification.

It was apparent to delegates that, by developing these four concepts, the principle which should govern basic training could be defined. The Danish and British delegations were assigned the task of preparing a joint statement on the concepts, principles and philosophy of the training of operators. The German delegation was requested to review present training programmes and then to prepare and circulate a questionnaire. Both groups were asked to report to the 1971 meetings in Stockholm.

A great deal of consideration was given to the problem of the selection of welders before entry into a training programme. Doc. XIV-286-70 “Aptitude testing for prospective welders" was discussed. While the Commission was not in favour of failing a candidate before he started the course, it was agreed that an unsatisfactory student should be eliminated before the end. A preliminary programme is already in operation in both the United States and the United Kingdom. It was agreed that, since both programmes were of such recent origin, delegations from the two countries would collaborate in the preparation of a report at a later date.

\section{Working Group-Classification and Qualification of Welding Operators}

Mr. Guyot (Belgium), Chairman of the Working Group, outlined the development of doc. XIV-282-70, which dealt with the classification and qualification of operators for metal arc welding of plates by manual and semi-automatic methods. The three parts forming this document had originally been submitted to the Commission in 1967 and 1968, and subsequently ap- proved and transmitted to ISO/TC $-44 / \mathrm{SC} 5$. The purpose of doc. XIV-282-70 had been to combine in a single document all the amendments and corrections approved by the Commission. Mr. Guyot outlined the future programme of the Working Group. This was :

(a) To complete the document on the qualification of pipe welders.

(b) To continue study of doc. XIV-282-70, taking into account documents XIV-293-70 and XIV295-70.

\section{Educational Aids}

The Commission noted that the fatigue monograph had finally been published in both French and English. The delay in the publication of these books has discouraged future authors from preparing documents for the IIW. It was also felt that a monograph on the teaching of welding technology was urgently needed. It was noted that doc. XIV-281-70 "American books on welding (revised list) 1967-December 31, 1969" was a constant source of information on teaching documents. Such documents are an important working tool which should be used by welding instructors to supplement current teaching programmes. Members of the Commission were recommended to discuss this matter with their temporary experts.

\section{Future Work}

The Commission is enthusiastically planning for the Assembly in Stockholm, at which the main theme will be training at engineer level. It was considered that a useful contribution was made by temporary experts and resolution 1 was passed with a view to continue this most useful association.

Members of the Commission were requested to prepare their documents long enough in advance to enable them to benefit fully from the help of their technical experts. Two interim meetings were planned: one for 15 and 16 October 1970 and one for 21 and 22 January 1971.

COMMISSION $X V$ - Fundamentals of design and fabrication for welding

Lausanne Assembly (Switzerland) : 13-17-July 1970

Chairman : Dr. A. AMIRIKIAN (USA)

\section{MEETINGS}

1. Main Commission. The Commission held its annual four-day working-sessions on 14 to 17 July 
1970, in conjunction with the 23rd Annual Assembly of the International Institute of Welding in Lausanne (Switzerland). Nearly 50 delegates, experts and observers from 18 countries comprising Belgium, Canada, Finland, France, Germany, Hungary, Italy, Japan, Netherlands, Poland, Rumania, Spain, Sweden, Switzerland, United Kingdom, U.S.A., U.S.S.R. and Yugoslavia, attended the sessions.

2. Sub-Commissions and Working Groups. With the exception of Sub-Commission C "Design for welding" all the groups of the Commission held one or more interim meetings during the past year, as follows :

(a) Sub-Commission A "Calculation of welded constructions subject to static loading" 12 December 1969 in Paris (France) 29-30 May 1970 in Warsaw (Poland)

(b) Sub-Commission $\mathrm{D}$ "Design of welded constructions in aluminium and aluminium alloys" 15-16 January 1970 in Paris (France)

(c) Sub-Commission E "Welded joints in tubular structures" 19 December 1969 in Paris (France)

(d) Working Group 3 "Classification of fusion welded joints for quality control" 14 January 1970 in Paris (France) 15 May 1970 in Genoa (Italy)

(e) Joint Working Group XIII/XV "Fatigue behaviour of welded structures" 13 January in Paris (France)

\section{PROCEedings}

As in former years, the sessions of the Annual Assembly in Lausanne provided the opportunity for review and discussion of the various activities of the Commission performed during the past year. The agenda of the sessions contained some 32 items, consisting of activity reports, new contributions, partially considered prior reports and papers, pending and future work plans, and various organisational matters. The following is a brief account of these proceedings, together with some supplementary background information pertaining to each group of activity.

1. Sub-Commission XV-A "Calculation of welded constructions subject to static loading"

Chairman : Prof. van Douwen (Netherlands)

\section{(a) Strength of fillet welds}

In the analysis of stresses in fillet welds, as for example when defining the critical stress $\left(\sigma_{\mathbf{c}}\right)$ by the
"ISO" formula, the question is often raised whether one should consider the effect of longitudinal stresses $(\sigma)$. Some years ago, in response to an inquiry by ISO regarding this matter, Commission XV expressed the opinion that such stresses can safely be omitted from the computations. Two papers on this subject, one entitled "The influence of a longitudinal stress $\left(\sigma_{u}\right)$ on the strength of fillet welds" (Doc. XV-274-69) and the other "The influence of a compressive longitudinal stress $\left(\sigma_{u}\right)$ on the strength of fillet welds" (Doc. XV-275-69), both describing related experiments conducted at the Stevin Laboratory of the Delft Ttchnical University (Netherlands) confirm this opinion. Based on these findings, the Commission reaffirmed its position by submitting to the Governing Council its resolution 3 , which was adopted; this resolution recommended that Sub-Committee 2 "Calculation of welded connections" of ISO/TC 44 "Welding" be informed that longitudinal stresses have no influence in the calculation of the static strength of fillet welds in mild steel and should therefore be neglected. The two documents mentioned above will be combined into one, which the Commission will examine next year and possibly recommend for publication.

The need for flange stiffeners in beam-to-column connections brings to attention another interesting problem, which is discussed in a paper entitled "The effective weld length of beam-to-column connections without stiffening plates" (Doc. XV-276-69). The findings of this investigation, which was also conducted at the Stevin Laboratory, indicate that, while the stiffener can be omitted, due to the non-uniform stress distribution of the resulting welded connection, the actual length of the weld must be reduced by a factor in order to convert it to an "effective weld length" of uniform strength. In the experiments, this reduction factor was obtained by taking the ratio of fracture loads of the non-stiffened and stiffened specimens. It was then observed that this effective length (1e) may be expressed as a function of web and flange thicknesses of the column and given in the general form in which

$$
1_{e}=2 \sigma+\alpha \beta
$$

$\sigma$ is the thickness of the web, $\beta$ that of the flange, the value of $\alpha$ varying according to the cross-sectional shape of the column and the type of the steel. For $\mathrm{H}$ shapes, the test gives a value of 8.0 and 6.4 for steels $\mathrm{Fe} 37$ and $\mathrm{Fe} 52$ respectively; and, with box shapes, of 6.4 and 4.8 respectively.

\section{(b) An aid in experimental investigations}

In structural tests in the laboratory, the influence of some of the variables or factors can more readily 
and economically be studied by computer simulation. A discussion of this problem is given in a paper by A. K. Lesniak (Poland) entitled "Application of the digital simulation for solving the strength of material problems" (Doc. XV-289-70). For illustration, the author makes use of the strength appraisal relation of a fillet-welded lap joint which was developed and presented in the final report of the International Test Series (Doc. IIS/IIW-330-69-Z (ex doc. XV-242-68)). Here the variables include the ultimate strengths of the base and weld metals and the ratio of actual to theoretical weld throat areas. The paper was recommended for publication (Resolution 1).

\section{(c) Reinforcements under load}

The question often arises whether it is practicable or effective to reinforce a framing member while it is under load through welding a reinforcing piece. According to the results of a series of tests, conducted at the Institute of Buildings in Bucharest (Rumania) and described in a paper by Prof. Dalban (Doc. XV298-70 "Essais surdes elements metalliques flechis renforces sous charges/Tests on reinforced loaded metal members") such a scheme is both feasible and effective. For this purpose, a number of I-beams were reinforced by the addition of a welded strip along the edge of each flange; in one case the strips were welded while the beam was under load; and the other in the unloaded conditions. No significant differences were observed in the load-deflection diagrams for the two cases, in both instances the yield moments and deflection being approximately of the same magnitude. Except for the possibility of premature failure by elastic bucking of the compression flange in the former case, the observed behaviour seems to be logical, since the plastic strength of the reinforced beam is but little affected by the sequence in which the various parts attain their plastic yields, Insofar as their ultimate strengths are concerned, two beams of the same cross sectional composition whether obtained in their preload or post-load conditions, may be considered as equivalent.

\section{(d) Stress distribution in fillet-welded connections}

In a paper entitled "Elastic and plastic stress distribution on base plates in the neighbourhood of fillet welds in lap joints" (Doc. XV-290-70) by K. Horikawa and T. Okumura (Japan), an attempt is made to determine analytically the stress concentration at the extremities of fillet-welded lap joints, both in the weld and the base metal. Using the finite element approach, the authors have made an elastoplastic analysis of three arrangements of splices, consisting of side welds, end welds and a combination of side and end welds, Utilizing the von Mises' concept of plane stress criterion and Pandit-Reusse's expression for stress-strain relation in the plastic range, they have found that the stress concentration factor, which is defined as the ratio of computed maximum stress at the ends to the nominal stress, may vary from 1.3 to 3.8 depending on the arrangement. In its resolution 4 , adopted by the Governing Council, Commission XV recommended the transmission of this document to Commission $\mathrm{X}$ "Residual stresses and stress relieving. Brittle fracture" and to Commission XIII "Fatigue testing". In addition, Sub-Commission XV-A will examine it in greater depth.

\section{(e) Joint restraints in welded assemblies}

A preliminary review was made of another interesting contribution from Japan, Doc. XV-292-70, entitled "Deformation and stress due to welding of typical welded joints in steel building" by F. Matsushita, H. Nakayama, M. Matsumoto and M. Inagaki (Japan). The study covers the extent of restraint introduced into the joints during welding of framing assemblies in the field, as well as the effect of deformations due to weld contraction of bolted connections. In the model assembly used for the investigation it was found that beam-to-column connection restraint was much smaller than that normally encountered in actual construction. It was also observed that such restraints would have little loosening effect on friction-type bolted connections and that ultrasonic inspections revealed no cracks in the welded joints. This paper will be referred to Sub-Commissions $\mathrm{A}$ and $\mathrm{C}$ for further study and comments.

\section{Sub-Commission XV-C "Design for welding"}

Chairman : Mr. P. Guiaux (Belgium)

Owing to his many pressing academic duties at the University, the new Chairman of the Group, which was reorganised and placed under his direction in 1968, had not been able to initiate activities prior to the Lausanne Assembly. At this meeting, he presented a tentative programme for the planned future work, covering mainly the needed revisions and elaborations of certain chapters of Doc. XV-72-58 "Recommendations for design of welded structures made by the arc welding process'. These are :

(a) Chapter 11 "Plates stressed in a direction perpendicular to their surface", which is concerned with the problem of possible 
laminar failure in welded joints by separation of layers of plating due to rolling defects or insufficient forging bond, when subjected to tension normal to their surfaces.

(b) Chapter 12 "Welding process compatibility with base material", which is concerned with problems generally associated with welded joint restraints in field assemblies, mainly in the form of under-bead and cold cracking.

(c) Chapter 13 "Choice of steel according to design and service conditions". In this task, a study will be made of another related document prepared by Sub-Commission F "Study of recommendations relating to steels for welded constructions" of Commission IX "Behaviour of metals subjected to welding" and entitled "Recommendations for classification of steels for use in welded structures" (Doc. IX-704-70). Also, an attempt will be made to gather information from international sources describing experiences and investigations concerned with the choice of steel as governed by considerations of economy, service behaviour and other influencing factors.

Additionally, it was suggested that the Sub-Commission prepare a new document on welded joint details, similar to that for welded aluminium construction of Sub-Commission XV-D.

The Commission, in approving the programme made a request to all members to submit pertinent data and information to Mr. Guiaux, to reach him well before the first meeting of his Sub-Commission, scheduled for this coming November.

\section{Sub-Commission XV-D "Design of welded con-} struction in aluminium and aluminium alloys"

\section{Chairman : Mr. H. Gerbeaux (France)}

After having completed its recent task of compiling a comprehensive treatise on welded construction in aluminium and aluminium alloys, which was recommended for publication as a separate brochure, the Sub-Commission has now prepared three supplementary documents in tabular form, bearing the following designations :

(a) Doc. XV-295-70 Table of principal aluminium alloys that can be used in welded construction with due regard to their weldability in relation to different welding brazing and soldering processes".

(b) Doc. XV-296-70 "Filler metals recommended for TIG, MIG and oxyacetylene welding of aluminium and its alloys in the wrought condition".

(c) Doc. XV-297-70 "Filler metals recommended for TIG and oxyacetylene welding of cast aluminium alloys".

It was recommended that these three documents be submitted for publication, preferably as an addendum or supplement to the preceding treatise on welded aluminium construction (Resolution 6).

As for future work, the Sub-Commission's agenda contains the following projects :

(a) A new chapter on "MIG welding" elaborating rules and regulations on the design of welded aluminium framings.

(b) A study of test results on welded assemblies of cast and wrought alloys.

(c) A document on electron-beam welding of aluminium alloys.

(d) A document on spot welding of aluminium alloys by the electric resistance method.

\section{Sub-Commission XV-E "Welded joints in tubular structures"}

\section{Chairman : Prof. A. A. Toprac (United States)}

The presentation of the Doc. XV-293-70, entitled "Research in the fatigue behaviour of tubular connections", by A. A. Toprac and B. G. Louis, was in reality intended as a progress report on the work of the Sub-Commission. As the concluding phase of a test series initiated some ten years ago, the paper is concerned with the fatigue strength of tubular members in welded $\mathrm{T}$-and $\mathrm{K}$-joint configurations. Among the numerous findings and recommendations of the investigation, the following are specially note-worthy :

(a) Due to severe stress concentrations traceable to the geometry of T-joints, their use should be avoided where fatigue conditions of loading prevail. 
(b) K-joints with overlapping braces present the most favourable arrangement under both static and fatigue loads.

(c) Test results obtained from small-size specimens were in good agreement with those of large-size specimens. Hence, in future research, the cost of experiments can be reduced by the use of small-size test pieces.

In a related paper, Doc. XV-291-70, entitled "Low cycle fatigue research on tubular K-joints" by $Y$. Kurobane, Y. Makino and M. Sagawa (Japan) results are given of a similar investigation where the study is confined to low-cycle alternating loads and $\mathrm{K}$-joint configurations only. In presenting their findings, again as a progress report of a continuing research, the authors express the belief that there is still need for further information regarding the behaviour of $\mathrm{K}$-joints under repetitive and fluctuating loads, particularly where the number of cycles is low and the average of the attained stresses relatively high, such as in the case of off-shore structures.

In view of the close relationship of these two papers, which are in fact complementary, since the former deals with high-cycle loading at lower stress ranges, before taking action on their publication, the Commission decided to request the Chairman of the Sub-Commission, Prof. Toprac, to review and combine the two papers into one document for reconsideration at the next annual meeting. In its resolution 5, adopted by the Governing Council, the Commission recommended the transmission of these two documents to Commission XIII for information.

As for future work, the Sub-Commission is of the opinion that it should now proceed with the preparation of a final document that will embody the information now available in this field and which could serve as an aid or the basis of a design specification for welded structures framed with tubular members.

\section{Working Group 3 "Classification of fusion Welded Joints for Quality Control"}

\section{Chairman : Dr. A. Erker (Germany)}

During its two interim meetings, the Group has reviewed and discussed a number of papers and proposals regarding the desired classification of joints for assuring the adequacy of their performance. However, in view of the diversity of factors and variety of types of structures, it has not as yet been able to formulate recom- mendations of general applicability. Presently, the Group is of the opinion that each category must be treated separately, and that each type of structure would thus have its own standards of weld quality control and assurance.

As a tentative recommendation that could be used in this task, it has been suggested that the joint be classified on the basis of the following five considerations :

(1) Degree of risk : Very high ; high ; medium ; none

(2) Type and level of stress : Dynamic ; static ; thermal ; corrosive High ; medium ; low ; negligible

(e) Weldability factors : Metallurgy ; geometry ; process ; none

(4) Extent of permissible defects : None ; small ; medium ; large

(5) Extent of needed inspection : $100 \%$; partial ; random ; none

The first paper elaborating this concept of quality control is Doc. XV-294-70 "Proposal for the classification of joints in cylindrical storage vessels not subjected to pressure" by H. Gerbeaux. In this treatment, the welds are first divided into four groups according to their types and locations; then after defining the various factors affecting their adequacy, a complete and rather rigid specification is given for types of defects and their limits of acceptability. After a preliminary examination of the paper, it was placed on the deferred list for further study and reconsideration in the future.

\section{Working Group XIII/XV "Fatigue Behaviour of Welded Structures"}

\section{Chairman : Dr. T. R. Gurney (United Kingdom)}

The initial activities of this Group under its new Chairman, Dr. Gurney, concern three principal tasks :

The first of these is an attempt to gather corroborative data on the rules and regulations governing the allowable stresses under fatigue loading, as now in effect in various countries. Replies to the initial inquiry have already been received from most of the countries contacted, and their study has indicated the need for further clarification, which is to be accomplished through a supplementary questionnaire. 
A second effort is to compile a catalogue of fatigue data obtained from general research performed in various countries. For this purpose, use is being made of pertinent references given in published works on the subject, such as those of Messrs. Munse (USA) and Gurney, and a brochure entitled "Monograph on the fatigue strength of welds", compiled by the Royal Swedish Academy of Engineering Sciences.

A third endeavour is concerned with a study of fatigue strength of fillet-welded joints made with welds of poor profiles. This is the programme suggested to Commission XIII as a first step of the project. In order to determine the magnitude of the experimental work needed, specimens for an exploratory test series are now being manufactured in Belgium.

\section{OTHER MATTERS}

\section{Liaison with ISO TC 44}

It will be recalled that ISO/TC 44 set up its Working Group 2 (which recently became Sub-Committee $10)$, whose terms of reference are the unification of requirements in the field of welding. The IIW's association with this Working Group has been mainly through representatives of Commission XV. In this capacity, Mr. Gerbeaux attended the ISO/TC 44 /WG 2 meeting held in Paris from 22 to 24 January 1970.

In addition, ISO/TC 44/WG 2 submitted in April 1970 a progress report on its activities for the consideration of the Plenary Committee Meeting of ISO/TC 44 held in Paris from 6 to 9 July 1970.

Working Group 3 of Commission XV commented on this document at its meeting of May 1970 in Genoa. Mr. Gerbeaux drew up a document summing up these opinions, which was brought to the attention of ISO/ TC 44 at its meeting of July 1970, which he attended.

At the Lausanne Assembly these comments (Doc. XV-300-70) were examined by the Commission, which felt that the proposals made by ISO/TC 44/WG 2 required a certain amount of revision as well as some additions in order to give a correct view of the present position with regard to knowledge and practice in the field of welded construction. As a member of Commission XV, Mr. Gerbeaux will continue to represent the IIW on Sub-Committee 10 of ISO/TC 44, and the necessary steps have been taken to ensure liaison in this connexion with Working Group 3 of the Commission.

\section{Working Group on Welded Light-Gauge Metal Structures}

The formation of the desired Working Group, still remains unaccomplished. However, Dr. Erker and his associates, who were charged with the initial organisational task, have now prepared a tentative programme outlining the scope of the contemplated work. According to this outline, the subject will be covered quite thoroughly. The application range will include buildings, aircraft, automobile bodies, railway rolling stock and many other structures built of light-gauge metal. A wide range is also envisaged for welding processes to be utilized in fabrication, comprising spot, seam, projection, flash, arc, gas, inert gas, and plasma.

Mr. Beatson, Chairman of Commission III "Resistance welding" has announced the appointment of Mr. V. Gregor of the Welding Research Institute of Bratislava, Czechoslavakia, as that Commission's representative to serve with the Group. The effort to obtain the services of assitional members, as well as of a permanent Chairman for the Group, continues.

\section{Chairmanship of Commission XV}

Professor, Soete, President of the International Institute of Welding, made two visits to the Commission, the first to inform members that the term of office of the present Chairman will expire in 1971, and therefore to ask for the Commission's suggestions regarding the choice of a candidate for the post, and the second to hear the opinions expressed on the subject. Despite the Chairman's earnest appeal for the selection of a cadidate other than himself, the Commission voted unanimously to request the reappointment of Dr. Amirikian for another term. The Chairman, deeply moved and appreciative of this mark of regard for and confidence in him, expressed some doubt whether he would be able to serve a full term. 